\title{
The dynamics of interdisciplinary research fields: the case of River Research
}

\author{
Pim Vugteveen*, Rob Lenders*, Peter van den Besselaar**,\# \\ * Department of Environmental Science, Radboud University, Heyendaalseweg 135, 6525 AJ Nijmegen, The Netherlands \\ ** Department of Organization Sciences \& Network Institute, VU University Amsterdam, Buitenveldertselaan 3, 1081 HV \\ Amsterdam, The Netherlands,
}

\# Corresponding author: p.a.a.vanden.besselaar@vu.nl

\begin{abstract}
Interdisciplinarity results from dynamics at two levels. Firstly, research questions are approached using inputs from a variety of disciplinary fields. Secondly, the results of this multidisciplinary research feed back into the various research fields. This may either contribute to the further development of these fields, or may lead to disciplinary reconfiguration. If the latter is the case, a new interdisciplinary field may emerge. Following this perspective, the scientific landscape of river research and river science is mapped to assess to which current river research is a multi-disciplinary endeavor, and to which extent it results in a new emerging (inter)disciplinary field of river science. The paper suggests that this two level approach is a useful method to study interdisciplinary research and, more generally, disciplinary dynamics.

With respect to river research, we show that it is mainly performed in several fields (limnology, fisheries \& fish research, hydrology \& water resources, and geomorphology) that hardly exchange knowledge. The different river research topics are multidisciplinary in nature, as they are shared by different fields. However, river science does not emerge as an interdisciplinary field, and often-mentioned new interdisciplinary fields such as hydroecology or hydromorphology are not (yet) visible. There is hardly any involvement of social within river research. Finally, the field of ecology occupies a central position within river research, whereas an expected engineering field is shown absent. This together may signal the acceptance of the ecosystem-based paradigm in river management, replacing the traditional engineering paradigm.
\end{abstract}

Keywords: cognitive change, knowledge dynamics, interdisciplinarity, multidisciplinarity, river science

\section{Introduction}

Recognition of system complexities and societal demands have challenged the science system to move away from traditional discipline-driven research towards a socially relevant and problem-driven mode of research that connects research activity across scholarly and societal boundaries (e.g. Kates et al. 2001; Gallopin et al. 2001). Understanding complex societal problems does challenge vertical boundaries between experts, policymakers, practitioners, and the public, and horizontal boundaries between disciplines (Van Kerkhoff 2005; Klein 2004; Nowotny et al 2003), and asks for cross-disciplinary research. For example, environmental issues typically are complex problems due to the interplay of phenomena at different temporal and spatial scales in social, economic and ecological dimensions. However, social and policy relevant research approaches do not emerge easily from existing disciplinary 
research. Despite its encouragement by research funders and science policy makers, the nature, status, and prestige of cross-disciplinary research remain unclear (Buter et al 2007).

In this study, we test a novel approach to cross-disciplinary research (Van den Besselaar forthcoming) by applying it to river research, a heterogeneous and societal relevant research domain. Doing so, we contribute to (a) better understanding of concepts of crossdisciplinarity, (b) better understanding of the dynamics of disciplinary change, and (c) the understanding of research domains that focus on results relevant for societal challenges - such as river science.

\section{Approaches to cross-disciplinary research}

Cross-disciplinary research (CDR) is attracting a lot of attention, as it is expected to produce more often societal relevant and scholarly innovative outcomes. Despite this, the meaning of the concept (and related concepts), and the indicators for identifying it, are still disputed. At the same time, in order to understand the claims about cross-disciplinarity, we need to understand its nature.

The terminology is still not stabilized, and concepts like multidisciplinary, interdisciplinary, and transdisciplinary are used in different ways by different authors. Furthermore, the terms multi/inter/trans/disciplinary are used in many different contexts, and seem to refer to many things, such as researchers, research groups or departments, individual papers and sets of papers, individual journals and sets of journals, research topics and scientific fields. So, one may talk about an interdisciplinary department, defined in terms of the disciplinary background of the members of the department, or in terms of the fields covered by the research of the department. And one may then ask whether the degree of interdisciplinarity of the department correlates with e.g., scholarly performance, or with interdisciplinary output, or with societal relevance of the research done by the group. Here we approach crossdisciplinarity from the perspective of the development of research fields.

We use cross-disciplinary as the generic term, and the other three in more specific ways, as will be argued in the paper (Van den Besselaar \& Heimeriks 2001; Merkx and Van den Besselaar 2007; Tress et al. 2005a).

Quite some work has been done over the years to develop concepts and indicators for crossdisciplinarity. Basically, two approaches can be distinguished. Many authors have defined cross-disciplinarity of a research field in terms of the share of references to other fields, i.e. in terms of the size of knowledge flows (Van Raan et al 2002; Rinia et al 2002). In this approach, the topology of the fields is generally based on top-down defined (Web of Science) subject categories, but sometimes bottom-up generated using some kind of similarity measure for papers or journals. In the latter case, only a part of the scientific landscape is generated, and therefore only a part of the knowledge flows can be taken into account. This approach focuses on the input for research, and on the integration of heterogeneous sources into crossdisciplinary research output (Porter et al 2006).

Others have defined cross disciplinarity as the change of the disciplinary landscape (Van den Besselaar et al 2001). This approach is based on mapping the disciplinary landscape bottom up, based on journal similarity measures (Van den Besselaar et al 1996). By comparing the disciplinary landscape between years, changes in research fields (growth, decline, merging, 
splitting, emerging, disappearing) become visible. The emergence of new fields can be read as an second order effect of CDR. The focus is on what could be called the these second order effects of CDR on the knowledge landscape through the development of new interdisciplinary fields.

We do not intend to discuss the whole CDR literature here (for reviews see e.g., Morillo et al, 2003; Bordons et al 2004; Zitt 2005; Wagner et al 2011), but contrast our approach with the recent work of Rafols and colleagues, which plays a central role in the current debate about CDR. They extended and generalized the first approach (e.g., Rafols, Leydesdorff, et al 2012; Liu, Rafols \& Rousseau 2012), and focus on interdisciplinarity as knowledge integration (Porter et al 2006). Their aim is to develop set of generic measures for interdisciplinarity, which has been applied on, for example, individual papers or sets of papers (Rafols \& Meyer 2010) and on research groups (Rafols, Leydesdorff, et al 2012). The approach deploys two (composite) indicators for the level of knowledge integration: diversity of knowledge inputs (which consists of variety, balance and disparity of the knowledge inputs) and coherence of knowledge inputs. A third indicator, betweenness centrality (now called intermediation), is used for measuring research that does not fit within existing fields - and therefore seems to adopt the topological approach. Although this work offers an interesting perspective on crossdisciplinarity, the approach has the following drawbacks:

(i) The diversity and coherence indicators depend on boundaries between fields, and for this one generally deploys the top-down fixed (WoS subject) categories. This implies that the dynamics of the disciplinary landscape is not taken into account, when calculating diversity and coherence. However, what is observed as variety, balance, disparity and coherence of, or intermediation between knowledge sources in terms of a fixed categorization of disciplines, may disappear if measured against a new and updated classification. In other words, for an adequate identification of CDR, it is necessary to have a full bottom-up (and therefore dynamic) definition of disciplinary stability and change.

(ii) The focus is on integration of knowledge sources used in cross-disciplinary research, so on inputs. However, disciplinary change as a possible effect of cross-disciplinary research activities is not taken into account. The results of CDR may get integrated in one of the disciplinary fields it is based on, or it may contribute to the development of emerging crossdisciplinary fields. So understanding of cross-disciplinarity not only needs to take into account the inputs, but also the uptake of the outputs at its effects.

(iii) The indicators for variety, balance, disparity and coherence measure the degree of crossdisciplinarity, but it is not so clear what that means - especially as the indicators should be updated in terms of disciplinary change.

(iv) Last but not least, the adoption of betweenness centrality (Leydesdorff 2007), or intermediation (Rafols, Leydesdorff, et al 2012) confuses the topological perspective with the relational. As well known, betweenness centrality measures "the extent to which a vertex lies on the path between other vertices" (e.g., Newman 2010, p185), which is not a topological characteristic. However, Leydesdorff calculates betweenness centrality through (i) setting a threshold, (ii) removing all similarities below the threshold, and (iii) calculating betweenness centrality for non-valued graphs on the resulting 'truncated' valued graph. This results in a kind of similarity measure - for which better alternatives are available (Van den Besselaar et al 1996, 2001). By using relational terminology for the position of the (cross-disciplinary) 
journal(s) between established fields, one suggests that the (cross-disciplinary) journal(s) function as broker (controlling the information exchange between the two fields) or as mediator (bringing the two fields together). And this is in fact generally not the case. ${ }^{1}$

Based on these considerations, we take a different approach. Cross-disciplinarity is here considered as disciplinary change, resulting from the interaction between two levels: the level of research where new knowledge is produced, and the level of knowledge communication where new knowledge claims are accepted and integrated into (sometimes changing) disciplinary frameworks (Van den Besselaar forthcoming).

At the level of disciplines, theoretical and methodological frameworks ("paradigms") are developing gradually, and sometimes radically, influenced by the outcomes of research. At the same time, these paradigms provide the researcher with a framework that structures the research activities. Normal science is the further development of the discipline through disciplinary research. However, researchers also explore new ways of answering questions often drawing from methods and ideas from other disciplines. Research questions are then approached in a multidisciplinary way using a diversity of inputs from a variety of disciplinary fields. The results of this multidisciplinary research feeds back into various research fields: through publications that are being cited (Fujigaki 2000). This may either contribute to the further development of the disciplinary fields the research is based on, or may lead to new developments outside those existing fields. Multidisciplinary research may sometimes generate a new - weak but identifiable - communication network. This takes the form of an initially small and not yet very coherent communication network consisting of a few journals for the new research. These journals are positioned between the disciplinary fields the new development is emerging from. In an earlier study we defined this as early stage interdisciplinarity, which may develop into more mature stages (e.g., artificial intelligence, neural networks, robotics) - or may disappear again (e.g., cognitive science). We showed that the structure of the communication network of mature interdisciplinary fields becomes identical to those of the traditional disciplines (Van den Besselaar et al 2001). In other words, interdisciplinarity is a temporary stage of disciplinary reconfiguration, as the further a new interdisciplinary field develops, the more disciplinary it becomes. Of course, these changes can only be observed if one avoids working with pre-defined fields. Definitions of research fronts and of fields and disciplines have to be dynamically based on similarities between journals and between papers.

In previous studies we focused on the development of the disciplinary landscape, operationalized as changing sets of journals ${ }^{2}$ with the same position in the global journal citation network (Van den Besselaar et al 1996, 2001). Here we combine this approach with an analysis of the development of CDR at the research front level, operationalized as

\footnotetext{
${ }^{1}$ An instructive example of the resulting confusion is a study by Goldstone \& Leydesdorff (2006) of cognitive science. Using betweenness centrality to measure the position of the journal Cognitive Science between computer science and cognitive psychology makes them conclude that the Cognitive Science functions as a broker between the two research fields, and that the knowledge flows between the two fields go through the journal Cognitive Science. However, the large majority of citations between the two fields are direct citations between journals in the two fields.

${ }^{2}$ It has been argued that in the current phase of scholarly publishing, the paper, more than the journals is the relevant unit. With direct (on line) access to articles, the journals would lose their central role in scholarly communication. If this would be the case, one would expect that journal citation networks are becoming less coherent over time. We tested this, and that does not seem to be the case. We will publish these results separately.
} 
communities of similar papers (Van den Besselaar et al 2006). A comparison of the paper network and the journal network will lead to an understanding of cross-disciplinarity as a twolevel process of change.

\section{The case: River research}

There is widespread recognition amongst scholars in environmental science that crossdisciplinary efforts are necessary to increase our understanding of complex environmental issues (Brierley and Fryirs 2008; Thorp et al. 2007; Wear 1999; Naiman 1999; Benda et al. 2002; Palmer and Bernhardt 2006; McCulloch 2007). Especially in the research and management of water systems, the bridging of disciplinary perspectives figures prominently on the agenda's, as evidenced by the promotion of fields like hydroecology, ecohydrology, eco-hydromorphology and eco-geomorphology. It has been suggested that these fields extend beyond ecology, geomorphology and hydrology into other contributing fields such as civil engineering, economics and social sciences (Vaughan et al. 2009; Hannah et al. 2004; Bond 2003; Thoms and Parsons 2002). These claims have been noted for coastal research (Merkx and Van den Besselaar 2008) as well as for river research (Van Hemert and Van der Meulen 2011).

However, when considering water research, interdisciplinary integration is still relatively uncommon (Hillman 2009). This has been attributed to the "turbulent" boundaries among different disciplines, a qualification that refers to mutual misunderstandings between disciplinary cultures, and to a lack of effective communication (Boulton et al. 2008). Interdisciplinary efforts tend to be perceived as being more complex for participants than traditional intra-disciplinary collaborations because participants have different paradigms and approaches (Cullen 1990; Benda et al. 2002; Petts et al. 2006).

In this paper we take the case of river research to study the dynamics of cross-disciplinarity. River research is a suitable case, as especially water-related issues call for the development of cross-disciplinary approaches to understand the systemic nature of the riverine landscape with its ecological, social, political, economic and cultural dimensions (Thorp et al. 2007; Lenders and Knippenberg 2005; Vugteveen et al. 2006). Following the approach outlined in the previous section, the landscape of river research is mapped using a combination of methods.

Firstly, we map the disciplinary landscape in which river science is embedded, based on the citation relations between the relevant journals. We test whether river science is developing into an interdisciplinary field, indicated by an emerging set of river research journals with similar referencing patterns.

Secondly, the citation links (the knowledge flows) between the relevant research fields are mapped, in order to measure the cross-disciplinary inputs for river research

Thirdly, we map the topical structure of the research front in river research at the paper level using similarity in terms of title words and references. Clusters of papers representing specific river research topics may be published within single disciplines, indicating a monodisciplinary approach, or published within different disciplines, indicating a multidisciplinary approach to those topics. 
Fourthly, the disciplinary environment and the topical structure of river research will be compared, and that leads to conclusions about the development of cross-disciplinarity in river research, and about its meaning for integrated river management.

\section{Methods and data}

\section{Document set}

Science can be viewed as a communication network. Journals as well as the scientific publications in journals allow us to map these communication systems. Journals are used for mapping the more global scientific landscape in terms of research fields around river research, whereas papers are used for mapping the research fronts, i.e. leading research topics. A variety of bibliometric techniques are available for this and will be used in this study. Fig. 1 presents a flowchart of the methodological steps, which are briefly outlined below.

In order to map current river research we started by using river* as a search term in order to retrieve all papers indexed in the Web of Knowledge with river* in title, keywords or abstract (step 1 in Fig. 1) ${ }^{3}$. The search was restricted to so-called citable items: articles, reviews, and proceedings papers (we use the commonly used term 'papers' to refer to all these document types for the remainder of the article). We searched multiple years (2007-2009) to avoid incidental citation relations. By using the simple generic search term river* we aimed for a high recall (but consequently a lower precision) of papers.

The resulting document set $(\mathrm{N}=31869)$ was used to identify the core river science journals by considering those journals with the highest shares of river related papers. Table 1 shows a listing of the journals in the set that are the most strongly focusing on rivers. Core journals are defined as (i) having more than $35 \%$ of their total paper output in the $2007-2009$ period belonging to the river* document set and (ii) having an absolute number of at least 100 papers in the document set. This selection was done because of pragmatic reasons, as we want to keep the journal maps readable. So we leave out a large number of less central and marginal journals. However, many of the journals that were excluded through the two criteria are still included in the analysis, as they do belong to the citation network of the core journals (see below).

\footnotetext{
${ }^{3}$ The use of river* may lead to a bias towards large, non-wadeable river systems and may partly exclude literature on the wadeable parts of the river system more commonly associated with terms such as 'streams'. To test, deploying 'stream*' as search terms resulted in a set documents that hardly overlapped (some 10\%) with the river* set. This is to a large extent because the term stream* has a much wider meaning. When restricting the stream* papers to the relevant subject areas (e.g., Environmental Sciences, Ecology, Water Resources, Marine Freshwater Biology, Oceanography, Biodiversity, Conservation, Physical Geography), the overlap increases to about $50 \%$ of the papers.
} 


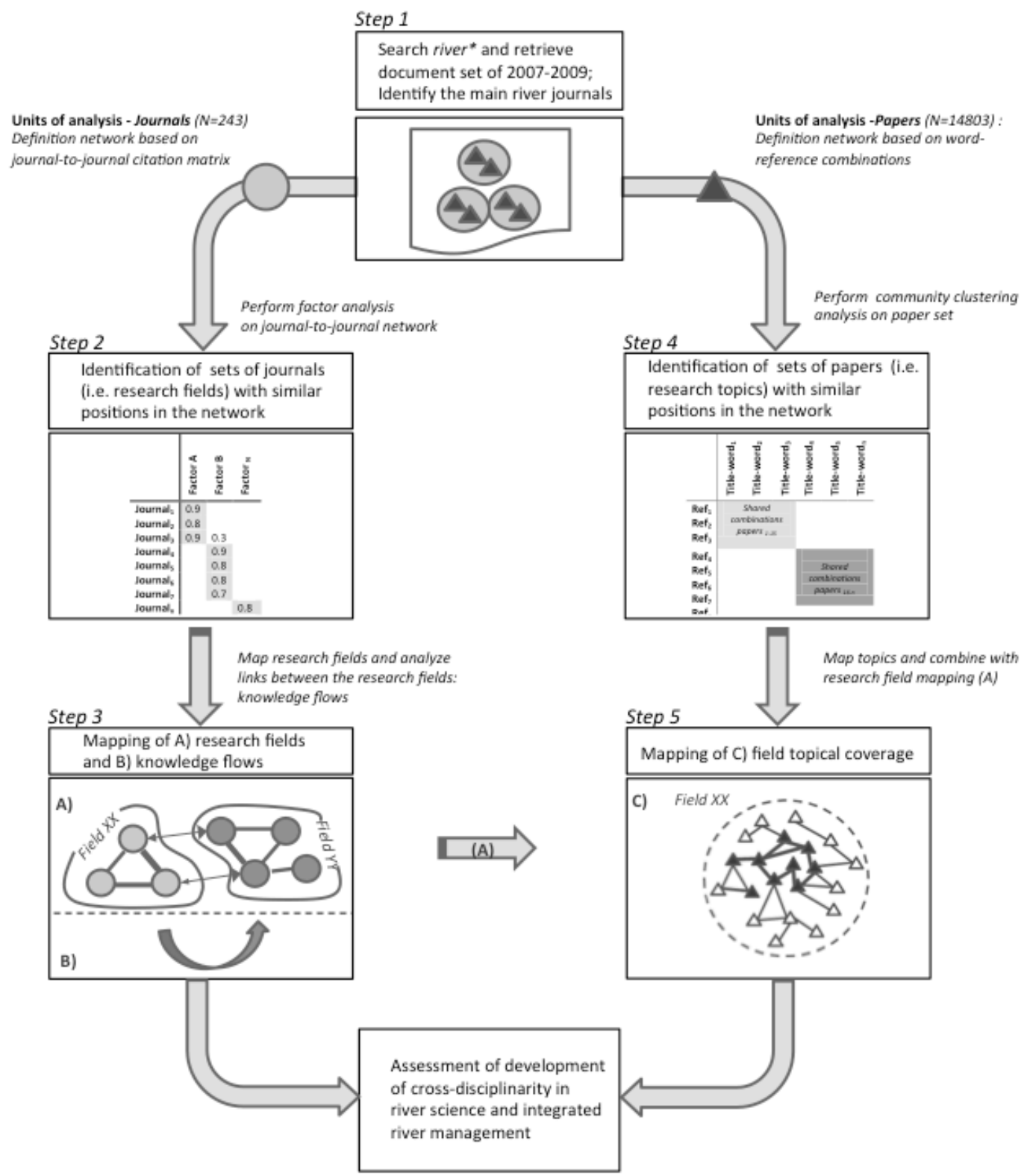

Fig. 1 Flowchart of methodological steps in study: A) Mapping of research fields (Fig 2); B) Analyzing knowledge flows between fields (Fig 3); C) Mapping of topical coverage (Fig 4). 
Table 1. Entrance journals for the citation analysis with river research papers (2007-2009).

\begin{tabular}{|l|l|l|l|l|}
\hline & Source title & \multicolumn{3}{|l|}{ River papers in document set } \\
\cline { 3 - 5 } & & $(\%)$ share & (\#) papers & (\%) repres \\
\hline 1. & River Research and Applications & 96 & 246 & 0.8 \\
2. & Ecology of Freshwater Fish & 59 & 108 & 0.3 \\
3. & Transactions of the American Fisheries Society & 48 & 206 & 0.6 \\
4. & Journal of the American Water Resources Association & 48 & 168 & 0.5 \\
5. & North American Journal of Fisheries Management & 44 & 192 & 0.6 \\
6. & Hydrological Sciences Journal & 42 & 105 & 0.3 \\
7. & Geomorphology & 41 & 379 & 1.2 \\
8. & Estuaries and Coasts & 41 & 119 & 0.4 \\
9. & Earth Surface Processes and Landforms & 41 & 187 & 0.6 \\
10. & Hydrological Processes & 40 & 411 & 1.3 \\
11. & Hydrology and Earth System Sciences & 39 & 163 & 0.5 \\
12. & Water Resources Management & 38 & 155 & 0.5 \\
13. & Freshwater Biology & 37 & 211 & 0.7 \\
14. & Journal of Hydrology & 35 & 474 & 1.5 \\
15. & Continental Shelf Research & 35 & 191 & 0.6 \\
\hline
\end{tabular}

For each journal the table presents i) the share (\%) of river papers across all published papers in the journal concerned, ii) the total number of papers and iii) the representation (\%) of the journal output across the total document set.

\section{Mapping research fields}

Journal citation networks are used for mapping research fields that are relevant for international river research (step 2 in fig. 1). The approach is based on the notion that researchers in a field share a set of research questions and methodologies and refer to a largely overlapping core literature. The use of a common knowledge base is reflected in the references. Consequently, journals belonging to the same research field exhibit similar aggregated citation patterns. The identity of the field can subsequently derived from the journal titles in the delineated cluster, and when needed with the help of field specialists (Van den Besselaar et al 1996, 2001). Using these citation-based communication patterns, we can retrieve the position of river science within the overall scientific landscape.

The analysis is based on the journal network of the 15 journals with the most river research papers (Table 1). We used the 2008 CD-Rom version of the Journal Citation Reports to compile the network. The network was constructed with all journals citing or being cited by the core 15 journals of Table 1. Since we were interested in structure and not in incidental citations, we removed the "noise" by discarding those journals that contributed less than $0.5 \%$ to the citations over 2008. Many of the journals that were not selected as core journal reappear in the analysis, as they belong to the (above threshold) citation environment of one or more of the 15 core journals. Factor analysis is a proven approach to find the main structure of a network (Hanneman and Riddle 2005) and for a journal network this represents the underlying landscape of research fields. Factor analyzing the matrix of $243 \times 243$ journals resulted in 23 factors, ${ }^{4}$ each representing a research field. The analytical question we pose is whether one of the factors represents river science, and the other factors do represent fields that are relevant for river science, or whether the core river science journals are distributed

\footnotetext{
${ }^{4}$ Though appearing in the factor analysis as a separate field we exclude Science Magazine, Nature and the Proceedings of the National Academies of Science from most of the further analysis of river science. These three journals have an explicit broad multi-disciplinary scope and are heavily cited by all fields, and that puts them together in a factor. However, they cannot be considered as representing a distinct research field.
} 
over a variety of fields. In other words, is river science a (emerging) single field or is river research cross-disciplinary and distributed across a set of distinct research fields?

\section{Mapping knowledge flows}

The next question is how the research fields that are relevant for river research are mutually related (step 3 in Fig. 1). Do these fields depend on each other, and how strongly? Numbers of citations between the different research fields (as represented by the factors) were calculated using the same journal-journal citation matrix. These citation relations are an indicator for knowledge flows and cross-disciplinary knowledge exchange, which can be analyzed in terms of their direction, their magnitude, and network configuration. For example, the more substantively a field is citing a range of heterogeneous other fields, the more crossdisciplinary it is considered to be.

\section{Mapping research topics}

To map the research topics within river science we selected from the initial 3-year document set only those documents $(\mathrm{N}=14,803)$ that were published in the 243 journals included in the factor analysis. Researchers simultaneously select (title) words to describe their research subject and references to relate to the tradition in which they work. These title words acquire their specific meaning within the context of the cited references. We used word-reference similarities between papers (Van den Besselaar and Heimeriks 2006) to map and analyze the topical structure of river research (step 4 in Fig. 1). The more combinations of title words and cited references are shared between papers, the more similar they are. Title words were reduced to their stem, which increased the accuracy of the clustering. ${ }^{5}$ For such a large set of papers, factor analysis cannot be used to cluster similar papers. Therefore we used the Saint tool (Somers et al. 2009) and a fast community detection algorithm (Blondel et al. 2008) to reveal 1340 clusters of topical similar papers, of which 108 have a reasonable size (defined as at least 15 papers over three years). For research topics with a social science nature we set a minimum of 5 papers. ${ }^{6}$ In total, slightly more than 10.000 papers (out of 14.803) are included in these 108 clusters.

In the final step the disciplinary structure and the topical structure of river science were compared by a superposition of the topics map on the field map (step 5 in Fig. 1). This shows the level of cross-disciplinarity of the research topics.

\section{Results}

\section{Mapping the relevant river science fields}

The 15 entrance journals have overlapping citation environments and together span a network of 243 journals. The factor analysis of the journal citation network reveals 23 factors,

\footnotetext{
${ }^{5}$ The nodes of the network are papers and the ties between papers are based on shared word-reference combinations: Title word $\mathrm{A}, \mathrm{B}$ to $\mathrm{N}$ are combined with cited reference 1,2 to $\mathrm{x}$ to form $\mathrm{A} 1, \mathrm{~A} 2, \ldots \mathrm{Ax} \mathrm{B} 1, \mathrm{~B} 2$, ....., Bx ... Nx. Similarity between papers depends on the number of shared combinations.

${ }^{6}$ For a more detailed explanation of clustering algorithms in general, see Palla et al (2005). For a comparative analysis of Blondel et al's algorithm versus others' see Lancichinetti and Fortunato (2009).
} 
representing research fields that constitute river science as well as several related research fields that provide knowledge input for river research (see for the result of the factor analysis: Online Resource 1). The factors are labeled according to the focus of the journals loading on that factor. This was done through inspecting the titles, which was then checked by field specialists (two of the authors).

The journal network consists of fields belonging to biology, geochemistry, environmental science (including environmental management), hydrology, and water resources research. Generally, journals load on one factor and have only a very low loading on other factors, indicating their mono-disciplinary nature. Journals that show a relatively high loading on different factors are cross-disciplinary, filling the space between the disciplines (Van den Besselaar et al 2001). For example, Global Planet Change loads 0.46 on oceanography, 0.34 on general environmental ecology, 0.47 on quaternary science, and 0.46 on climatology. Also River Research and Applications shows a typical multidisciplinary behavior, as it loads moderately on more factors: 0.61 on limnology and 0.40 on fisheries \& fish research. On the other hand, the ecology journals and the hydrology \& water resource journals hardly load on a second factor, indicating that these research fields have a strong disciplinary identity.

Table 2. Core fields in river science 2007-2009

\begin{tabular}{|c|c|c|c|c|}
\hline Rank & Label & (\%) share & \# river papers & (\%) mass \\
\hline 1. & Limnology & 37.6 & 1493 & 10.1 \\
\hline 2. & Fisheries \& fish research & 27.6 & 1456 & 9.8 \\
\hline 3. & Hydrology \& water resources & 27.1 & 2532 & 17.1 \\
\hline 4. & Geomorphology & 26.2 & 850 & 5.7 \\
\hline 5. & Sediment geology & 19.6 & 210 & 1.4 \\
\hline 6. & Geochemistry & 16.4 & 813 & 5.5 \\
\hline 7. & Quaternary science & 14.2 & 538 & 3.6 \\
\hline 8. & Environment pollution & 13.7 & 1676 & 11.3 \\
\hline 9. & Marine \& estuarine biology & 12.1 & 1112 & 7.5 \\
\hline 10. & Environmental management & 10.8 & 232 & 1.6 \\
\hline 11. & Water science \& technology & 10.5 & 550 & 3.7 \\
\hline 12. & Soil science \& agricultural water & 9.6 & 388 & 2.6 \\
\hline 13. & Geology & 7.8 & 313 & 2.1 \\
\hline 14. & Oceanography & 7.8 & 733 & 4.9 \\
\hline 15. & General environmental ecology & 7.3 & 62 & 0.4 \\
\hline 16. & Ecology & 7.0 & 860 & 5.8 \\
\hline 17. & Aquaculture & 7.0 & 248 & 1.7 \\
\hline 18. & Climatology & 6.8 & 221 & 1.5 \\
\hline 19. & Evolutionary ecology & 5.9 & 193 & 1.3 \\
\hline 20. & Remote sensing & 4.2 & 158 & 1.1 \\
\hline 21. & Microbiology & 3.3 & 126 & 0.9 \\
\hline \multirow[t]{2}{*}{22.} & Behavioral ecology & 0.7 & 39 & 0.3 \\
\hline & & SUM & 14.803 & 100 \\
\hline
\end{tabular}

Document set 2007-2009 from journals drawn in the factor analysis. For each field the share (\%) and absolute number of river papers across all published papers in the subsequent field journals is presented, as well as the mass (\%) of the field across the river science document set.

The fifteen major river science journals (Table 1) are not concentrated in one factor but are distributed across multiple fields. Hydrology \& water resources contains six of the entrance journals, fisheries $\&$ fish research three, limnology and geomorphology each contain two, and marine \& estuarine biology and oceanography each include one. The citation analysis thus 
shows that river science does not constitute a separate discipline but is a multidisciplinary endeavor. Based on their share of river related papers, i.e. the degree to which the research fields contribute to river science, the first four of these five fields can indeed be considered as core fields for river science (Table 2).

Based on absolute numbers of papers, hydrology \& water resources ranks, as expected, highest as a major contributor to river science. Environmental pollution is also a significant field as it has a large contribution to the document set in absolute terms. River systems may be a major object, but are not core object of research in environmental pollution, which is reflected in the relatively low amount of river papers compared to its total output. Limnology and fisheries \& fish research are also among the major contributors as well as marine \& estuarine ecology, the latter adding significantly to the number of river related publications.

Fig. 2 presents a visualization of the results of the factor analysis, and shows the way the research fields are positioned in and around river science. ${ }^{7}$ The nodes represent journals while the thickness of the links is a measure of the degree of similarity in citation behavior between the two nodes. Research fields are represented by (factor analysis-based) groups of journals within the larger network. The denser the network is (and the thicker the lines), the stronger the disciplinary orientation of a research field. Fig. 2 reveals which fields are similar to each other in terms of citation patterns. These so called meta-fields are:

(i) Ecological sciences, situated on the right side of the map. Ecology is in the middle, surrounded by different river science fields: limnology, marine and estuaries biology, with fisheries \& fish research and aquacultures clustering at the far right. Also general environmental ecology, and evolutionary ecology are in this part of the map;

(ii) Geosciences, at the left of the map, including geology, sedimentology, quaternary sciences and climatology;

(iii) Environmental pollution and Water science \& technology, in the left-bottom corner;

(iv) Hydrology \& water resources, center bottom the map. The map shows that this field has a strong own citation identity; separated from the other fields and having a dense network structure.

Several other fields that are relevant for river science can be found on the map. Geochemistry is in the center of the map, between geosciences and hydrology. At the edges we find Microbiology, and Behavioral ecology. In the right top, close to the Geosciences, we find Remote sensing. Finally, Environmental management is in the lower middle of the map.

Concluding, river science has not developed into an early or mature interdisciplinary field, but consists of a few fields in which river research has an important position. River research and main journals publishing about it are distributed across hydrology (six journals), the various ecology fields (seven journals), and geosciences (two journals).

\footnotetext{
${ }^{7}$ Please note that this is a two dimensional map of a multidimensional space. The projection influences the distances between the fields on the map.
} 


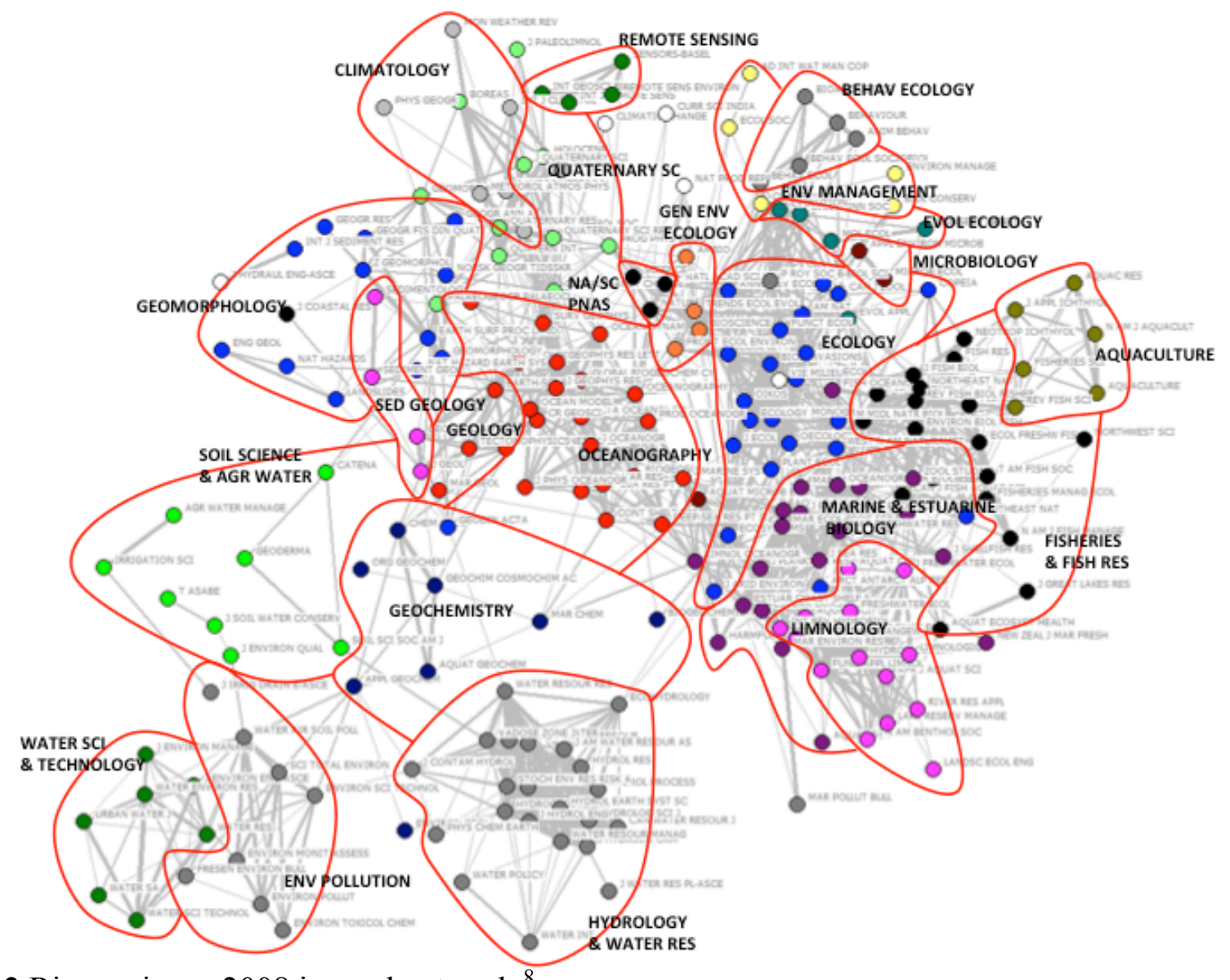

Fig. 2 River science 2008 journal network. ${ }^{8}$

\section{Mapping of knowledge flows between the fields}

The various research fields have mutual citation relations whereby the more field A cites field B, C, D etc., the more it depends on these other research fields. The observed meta-fields that compose river science present themselves clearly when considering the knowledge flows (citation relations) between the fields. Fig. 3 presents a visual representation of these relations, and Online Resource 2 supplies the underlying data.

The eco-sciences meta-field includes ecology and more specialized fields such as human environmental ecology, ecological genetics, evolutionary- and behavioral ecology.

Environmental management has the strongest citing relations with ecology. The meta-field further includes aquatic ecology \& biology fields such as limnology and marine \& estuarine biology, and fisheries \& fish research and aquaculture. Within the eco-sciences the field of ecology is central and presents a so-called reference field for other eco-fields as it is being cited substantively, as well being cited by other fields throughout the whole network.

Furthermore there is an environmental pollution and water science \& technology grouping consisting of hydrology and soil science \& agricultural water research, and also a geoscience meta-field including a subgrouping of oceanography and climatology. The geoscience metafield is quite separate from the eco-science meta-field in which oceanography and geology present reference fields. Finally, we found hydrology and soil water as a fourth meta-field.

\footnotetext{
${ }^{8}$ The nodes represent journals. Dense and thick links between nodes represent high similarity in citing behavior.
} 


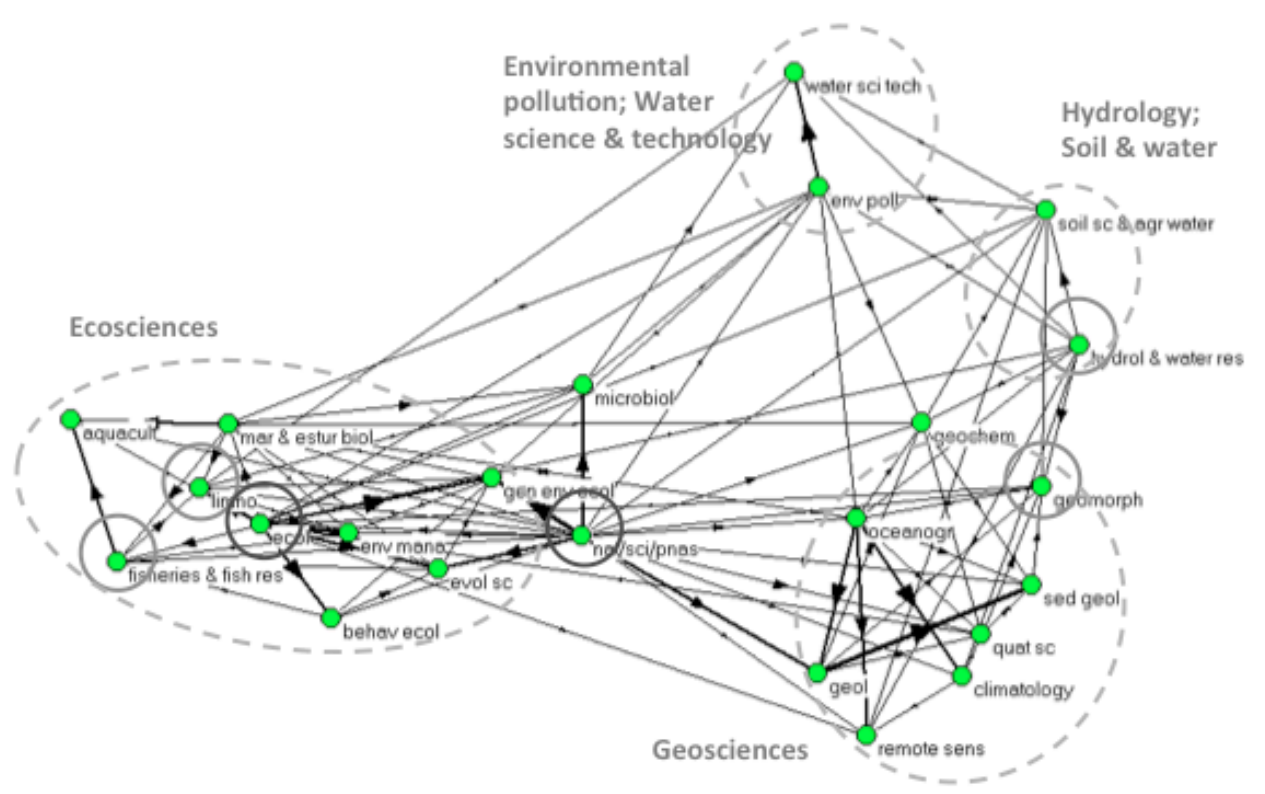

Fig. 3 Knowledge flows between research fields. ${ }^{9}$

One may classify a field as cross-disciplinary when it is substantively citing a range of other fields belonging to different meta-fields. From inspecting the knowledge flows across these meta-fields it appears however that the citation relations within the four meta-fields are rather tight, whereas the cross-disciplinary exchange between the four meta-fields is much more limited. For example the environmental pollution and water science $\&$ technology meta-field does show citation relations to the eco- and geosciences meta-fields but to a very limited extent.

We have identified river science as a multidisciplinary activity within hydrology \& water resources, limnology, fisheries $\&$ fish research and geomorphology. When we consider these core fields (light grey circles in Fig. 3), hydrology \& water resources presents a distinct research field that is mainly self-citing $(60 \%)$ and has links to both the environmental pollution meta-field as well as the meta-field of geosciences. The most substantial mutual citing relation is shown with soil science $\&$ agricultural water. The citation relations with the other three mentioned core river science fields are small or absent. Limnology and fisheries \&

\footnotetext{
${ }^{9}$ The nodes represent the fields. The dashed circles indicate meta-fields. Thickness of the arrowhead and distance between fields express the strength of the flows. The closer together, the stronger the mutual knowledge flows. The light gray circles indicate the four fields that include the core of river science. The dark grey circle in the center of the map indicates Science Magazine, Nature, and the Proceedings of the National Academies of Science. As expected, these journals are cited by (almost) all other fields, and therefore get a position in the center of the map. The second dark circle is the ecology field, a center field in the eco-sciences.
} 
fish research belong to the same grouping - but hardly cite hydrology \& water resources and geomorphology. Finally, geomorphology heavily cites hydrology \& water resources (and not the other way around) but does not cite fisheries \& fish research and limnology (see Online Resource 2 for further details). In other words, the different river research fields are not strongly connected in terms of knowledge exchange.

\section{Mapping of river research topics}

So far we mapped river science on a high level of aggregation: as a network of research fields, based on the relevant journals. Using the published papers as unit for mapping we now proceed by producing a more detailed map of river research. Clustering papers through title word-cited reference similarity we derived the main research topics in river science over the last few years, i.e. the research front. Table 3 gives an overview of the 38 largest topics out of 108 main research topics we identified in the document set.

The research topics cover fish, climate, river evolution and pollution issues. Specifically, the distribution and diversity of fish assemblages in relation to habitat changes presents a large topic in the set, followed by hydrological modeling in the context of climate change. Table 4 also shows that many major topics in river science are focusing on different forms of environmental pollution. Furthermore, topics focuses on fish migration, sediments multiple topics address systemic relations, specifically ecological and geomorphological cycles as well as hydrological interactions and dynamics.

Table 3 shows which research fields contribute to the various topics. It can be seen that most of the topics are the research domain of multiple fields indicating cross-disciplinary research endeavors. Some topics are explicitly the object of study for a single field, for example in environmental pollution (e.g. nos. $7 \& 14$ ), hydrology \& water resources (e.g. nos. 2, 12) and fisheries \& fish research (e.g. nos. 22, 24). Above, we observed that fields like hydrology \& water resources and environmental pollution show high self-citing behavior suggesting monodisciplinarity. But also the topics that have cross-disciplinary orientation remain within a single meta-field. These findings suggest that cross-disciplinary interaction across broader scientific meta-fields is limited. This is in line with the analysis of knowledge flows presented above.

Despite the discussions on the relevance of social research (such as planning, management, economics) for river research and management, the fields map (Fig. 2) only included one such field: environmental management. The topics list (Table 3) does not show any social science topics. By investigating the presence and nature of 'societal' research topics in river scientific output in detail, more insight is gained in the position of social science within river research. Using a title word search ${ }^{10}$, a total of 38 different topics were identified of which Table 4 shows the major ones. These topics relate to integrated water management, planning, system approaches, water sharing \& trade, and user/stakeholder perspectives. The focus is on (integrated) water management and related topics, with clear policy relevance. Over half of the social topics are related to the field of hydrology \& water resources and are published in

\footnotetext{
${ }^{10}$ We used an automated search on the following search terms and derivatives (based on an inspection of the title words frequency distribution): agencies, cost, decision, development, economic, institution, learning, management, participant, place, planning, policy, public, social, socio, stakeholder, strategy, sustainability, user. The remaining topics were manually and visually checked.
} 
Table 3. Major river science research topics having at least 50 papers. Per topic the contributions (\%) of metafields and single fields to the topical paper set (third column) is presented.

\begin{tabular}{|c|c|c|c|c|c|c|c|c|c|}
\hline \multirow[b]{2}{*}{$\mathrm{Nr}$. } & \multirow[b]{2}{*}{ Topics } & \multirow[b]{2}{*}{$\begin{array}{l}\text { Nr. of } \\
\text { papers }\end{array}$} & \multicolumn{4}{|c|}{ Meta-field* (\%) } & \multirow[b]{2}{*}{$\begin{array}{l}\text { Most contributing } \\
\text { field }\end{array}$} & \multirow[b]{2}{*}{$\begin{array}{l}\text { Share } \\
(\%)\end{array}$} & \multirow[b]{2}{*}{ All contributing fields $(5 \%)^{* *}$} \\
\hline & & & 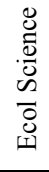 & 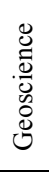 & $\begin{array}{l}\overline{0} \\
\infty \\
\infty \\
ث \\
\vec{\Xi} \\
\vec{\Xi}\end{array}$ & $\begin{array}{l}\bar{D} \\
0 \\
\infty \\
\infty \\
0 \\
\infty \\
3\end{array}$ & & & \\
\hline 1 & fish assemblages - habitat effects & 1436 & 83 & 3 & 6 & 8 & limnology & 37.7 & $5 ; 7 ; 9 ; 13 ; 14 ; 15$ \\
\hline 2 & hydrol modeling - climate change & 1349 & 5 & 21 & 67 & 7 & hydrology \& water res & 61.8 & $3 ; 13 ; 21$ \\
\hline 3 & river flow - fish \& vegetation effects & 714 & 64 & 15 & 16 & 5 & limnology & 29.6 & $5 ; 9 ; 11 ; 13 ; 14$ \\
\hline 4 & salmon trout - population genetics & 474 & 98 & 1 & 0 & 1 & fisheries \& fish res & 31.9 & $1 ; 5 ; 8 ; 9 ; 14 ; 15$ \\
\hline 5 & holocene river evolution & 464 & 5 & 91 & 5 & 0 & quaternary science & 43.3 & $4 ; 11 ; 18 ; 20$ \\
\hline 6 & river sediments & 318 & 14 & 70 & 11 & 5 & oceanography & 24.8 & $4 ; 11 ; 13 ; 15 ; 17 ; 18 ; 20$ \\
\hline 7 & heavy metal pollution & 263 & 6 & 28 & 9 & 57 & env pollution & 51.7 & $7 ; 10 ; 21$ \\
\hline \multirow[t]{2}{*}{8} & dissolved organic carbon & 246 & 29 & 29 & 15 & 27 & env pollution & 20.7 & $7 ; 10 ; 13 ; 14 ; 15 ; 17 ; 22$ \\
\hline & estuarine phytoplankton-nutrient & & 71 & 14 & 2 & 14 & & & \\
\hline 9 & dynamics & 227 & & & & & mar \& est biol & 49.3 & $7 ; 14 ; 15 ; 17$ \\
\hline 10 & river basin weathering & 200 & 3 & 77 & 14 & 7 & geochemistry & 47.5 & $4 ; 7 ; 10 ; 13 ; 17$ \\
\hline 11 & river sediments - organic matter & 186 & 19 & 69 & 2 & 9 & geochemistry & 32.3 & $7 ; 10 ; 15 ; 17$ \\
\hline 12 & groundwater-surface water interactions & 186 & 20 & 9 & 64 & 7 & hydrology \& water res & 61.3 & $7 ; 13 ; 14$ \\
\hline 13 & river bed - transport & 168 & 4 & 57 & 38 & 2 & geomorphology & 44.6 & $11 ; 13 ; 20$ \\
\hline 14 & mercury contamination & 166 & 16 & 17 & 3 & 64 & env pollution & 62.0 & $7 ; 10$ \\
\hline 15 & estuarine plume modeling & 152 & 23 & 67 & 7 & 4 & oceanography & 58.6 & $13 ; 15 ; 17$ \\
\hline 16 & flow modeling - artificial neural network & 148 & 7 & 4 & 80 & 8 & hydrology \& water res & 78.4 & 13 \\
\hline \multirow[t]{2}{*}{17} & nitrogen phosphorus effects & 142 & 40 & 19 & 33 & 8 & soil science & 16.9 & $5 ; 7 ; 10 ; 13 ; 14 ; 15 ; 16 ; 21$ \\
\hline & polycyclic aromatics \& hydrocarbons & & 9 & 8 & 3 & 80 & & & \\
\hline 18 & distr. & 127 & & & & & env pollution & 74.8 & $7 ; 15 ; 22$ \\
\hline 19 & food web - trophic levels isotopes & 105 & 87 & 4 & 0 & 10 & mar \& est biol & 45.7 & $5 ; 7 ; 9 ; 14 ; 15$ \\
\hline 20 & nutrients - agricultural loading & 105 & 16 & 12 & 47 & 25 & soil science & 23.8 & $7 ; 10 ; 13 ; 14 ; 17 ; 21 ; 22$ \\
\hline 21 & groundwater - isotopes & 100 & 7 & 49 & 42 & 2 & hydrology \& water res & 42.0 & $10 ; 13 ; 18$ \\
\hline 22 & salmon trout - habitat & 96 & 97 & 2 & 0 & 1 & fisheries \& fish res & 59.4 & $5 ; 9 ; 14$ \\
\hline 23 & wastewater treatment - pharm occurrence & 81 & 2 & 0 & 5 & 93 & env pollution & 65.4 & $7 ; 22$ \\
\hline 24 & sturgeon, green - habitat use & 79 & 97 & 0 & 0 & 3 & fisheries \& fish res & 54.4 & $1 ; 9$ \\
\hline 25 & eel migration & 76 & 97 & 1 & 0 & 1 & fisheries \& fish res & 55.3 & $9 ; 14 ; 15$ \\
\hline \multirow[t]{2}{*}{26} & water quality assessment - pollution & 75 & 4 & 5 & 25 & 65 & env pollution & 44.0 & $7 ; 10 ; 13 ; 22$ \\
\hline & salmon trout, atlantic - migration \& & & 97 & 0 & 0 & 3 & & & \\
\hline 27 & survival & 74 & & & & & fisheries \& fish res & 64.9 & $1 ; 9 ; 14 ; 15$ \\
\hline 28 & river sediments - transport & 72 & 6 & 33 & 51 & 10 & hydrology \& water res & 43.1 & $7 ; 11 ; 13 ; 21$ \\
\hline 29 & salmon, pacific - migration \& spawning & 70 & 97 & 1 & 1 & 0 & fisheries \& fish res & 45.7 & $5 ; 6 ; 8 ; 9$ \\
\hline 30 & mekong delta - arsenic pollution & 65 & 0 & 62 & 14 & 25 & geochemistry & 56.9 & $7 ; 10 ; 13$ \\
\hline \multirow[t]{2}{*}{31} & wastewater treatment - hormones & 58 & 3 & 0 & 3 & 93 & env pollution & 81.0 & $7 ; 22$ \\
\hline & river - estuary interaction - tidal & & 30 & 59 & 2 & 9 & marine \& estuarine & & \\
\hline 32 & circulation & 56 & & & & & biology & 50.0 & $13 ; 15 ; 17$ \\
\hline 33 & carbon fluxes & 56 & 50 & 41 & 7 & 2 & oceanography & 35.7 & $7 ; 10 ; 15 ; 17$ \\
\hline \multirow[t]{2}{*}{34} & fish otolith chemical composition & 54 & 96 & 2 & 0 & 2 & fisheries \& fish res & 55.6 & $9 ; 15$ \\
\hline & integrated water management - social & & 25 & 0 & 58 & 17 & & & \\
\hline 35 & learning & 53 & & & & & hydrology \& water res & 56.6 & $6 ; 13 ; 22$ \\
\hline \multirow[t]{2}{*}{36} & leaf - litter decomposition & 53 & 91 & 0 & 0 & 9 & limnology & 66.0 & $5 ; 7 ; 14 ; 15 ; 16$ \\
\hline & polychlorinated \& brominated substance & & 0 & 0 & 2 & 98 & & & \\
\hline 37 & distr. & 50 & & & & & env pollution & 98.0 & 7 \\
\hline 38 & pesticides distribution & 50 & 4 & 0 & 6 & 90 & env pollution & 84.0 & $7 ; 21 ; 22$ \\
\hline
\end{tabular}

* Meta-field definition follows from identified factors (Figure 2) and knowledge flows (Figure 3). The meta-field with the highest share is shown in bold.

** Fields contributing $5 \%$ to the topic paper set are presented as well as the most contributing field and its respective share. Identification of contributing fields, i.e. research field representation, is based on the journal affiliations of topic papers and their respective identified factorial research fields. ${ }^{*} 1=$ aquaculture; $2=$ behavioral ecology; $3=$ climatology; $4=$ geology; $5=$ ecology; $6=$ environmental management; $7=$ environmental pollution; $8=$ evolutionary ecology; $9=$ fisheries $\&$ fish research; 10= geochemistry; 11= geomorphology; $12=$ general environmental ecology; $13=$ hydrology \& water research; 14= limnology; $15=$ marine \& estuarine biology; 16= microbiology; $17=$ oceanography; $18=$ quaternary science; $19=$ remote sensing; $20=$ sediment geology; $21=$ soil science; $22=$ water science $\&$ technology 
the more general water resource (management) oriented journals such as Water Resources Management and Water Policy. Other societal topics are within environmental management and in water science and technology. Interestingly, although societal issues are being discussed in the river research literature, there is no significant reference to social science literature as no factor with social science journals was found.

Table 4. Major social issues research topics having at least 5 papers. Per topic the contributions (\%) of metafields and single fields to the topical paper set (third column) is presented.

\begin{tabular}{|c|c|c|c|c|c|c|c|c|c|}
\hline \multirow[b]{2}{*}{$\mathrm{Nr}$. } & \multirow[b]{2}{*}{ Topic } & \multirow[b]{2}{*}{$\begin{array}{l}\text { Nr. of } \\
\text { papers }\end{array}$} & \multicolumn{4}{|c|}{ Meta-field* $(\%)$} & \multirow[b]{2}{*}{$\begin{array}{l}\text { Most contributing } \\
\text { field }\end{array}$} & \multirow[b]{2}{*}{$\begin{array}{l}\text { Share } \\
(\%)\end{array}$} & \multirow[b]{2}{*}{$\begin{array}{l}\text { All contributing } \\
\text { fields* }\end{array}$} \\
\hline & & & 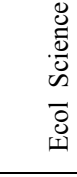 & $\begin{array}{l}\stackrel{O}{0} \\
\stackrel{0}{0} \\
0 \\
0 \\
0\end{array}$ & 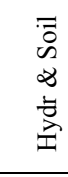 & $\begin{array}{l}\overline{\bar{o}} \\
0 \\
\infty \\
0 \\
0 \\
3\end{array}$ & & & \\
\hline 1 & integrated water management - social learning & 53 & 25 & 0 & 58 & 17 & hydrol \& water res & 57 & $6 ; 7 ; 13 ; 21 ; 22$ \\
\hline 2 & integrated water management - allocation & 24 & 4 & 0 & 88 & 8 & hydrol \& water res & 83 & $6 ; 13 ; 21 ; 22$ \\
\hline 3 & conservation planning & 19 & 84 & 0 & 5 & 11 & env mana & 58 & $5 ; 6 ; 14 ; 21 ; 22$ \\
\hline 4 & integrated water management - governance & 14 & 0 & 0 & 86 & 14 & hydrol \& water res & 86 & $13 ; 22$ \\
\hline 5 & coping with floods & 10 & 10 & 70 & 10 & 10 & geomorph & 70 & $6 ; 11 ; 13 ; 22$ \\
\hline 6 & water sharing - disputes \& cooperation & 10 & 0 & 0 & 100 & 0 & hydrol \& water res & 100 & 13 \\
\hline 7 & water resources - economics & 8 & 25 & 0 & 50 & 25 & hydrol \& water res & 50 & $5 ; 13 ; 22$ \\
\hline 8 & virtual water trade & 7 & 0 & 0 & 71 & 29 & hydrol \& water res & 71 & $13 ; 22$ \\
\hline 9 & stakeholder water demands & 7 & 14 & 0 & 29 & 57 & water sci tech & 57 & $13 ; 14 ; 22$ \\
\hline 10 & integrated urban management: systems approach & 7 & 0 & 14 & 29 & 57 & water sci tech & 57 & $3 ; 13 ; 22$ \\
\hline 11 & planning under uncertainty & 7 & 0 & 0 & 86 & 14 & hydrol \& water res & 71 & $13 ; 21 ; 22$ \\
\hline 12 & balancing water needs & 7 & 14 & 14 & 57 & 14 & hydrol \& water res & 57 & $10 ; 12 ; 13 ; 22$ \\
\hline 13 & EU Water Framework Directive & 6 & 17 & 33 & 17 & 33 & geochem & 33 & $6 ; 7 ; 10 ; 13 ; 22$ \\
\hline 14 & trading discharge permits & 6 & 17 & 0 & 50 & 33 & hydrol \& water res & 50 & $6 ; 7 ; 13 ; 22$ \\
\hline 15 & water markets & 6 & 0 & 0 & 100 & 0 & hydrol \& water res & 83 & $13 ; 21$ \\
\hline 16 & recreation management & 5 & 80 & 0 & 0 & 20 & env mana & 40 & $1 ; 6 ; 9 ; 22$ \\
\hline 17 & flood vulnerability: informing policy & 5 & 0 & 20 & 20 & 60 & water sci tech & 60 & $3 ; 13 ; 22$ \\
\hline
\end{tabular}

* Meta-field definition follows from identified factors (Figure 2) and knowledge flows (Figure 3). The meta-field with the highest share is shown in bold. Social topics were identified based on "socially-relevant" title words. *see legend of Table 3

Tables 3 and 4 show that some topics predominantly belong to a single research field whereas most topics are researched by a variety of fields. Differences and similarities in topical relations of research fields are further visualized in Fig. 4 representing a topics map based on similarities in terms of word-reference combinations. This means that papers of similar topical scope are clustered. Related topics are close to each other, whereas unrelated topics are farther apart. A so-called 'spring model' algorithm fitted all articles into a 2D visualization, using the BibTechMon visualization tool (Kopcsa and Schiebel 1998).

On this topics map a field map was superimposed. For clarity reasons we partitioned the mapping and produced separate maps for each research field. For each field (= a set of journals) all papers belonging to the field are colored. This way of presenting and visualizing allows for comparisons between fields and it reveals that the topical scopes of research fields differ in range and structure. In some field maps, papers are concentrated indicating a more homogeneous topical structure of the field. This is true for smaller fields like evolutionary ecology and climatology. Other fields show a more heterogeneous topical structure like ecology and environmental pollution. Multi-disciplinary topics (Table 3) are indicated where colored areas in field maps show overlap. For example limnology and marine \& estuaries biology partly cover the same topics. 


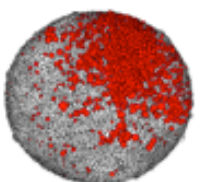

limnology

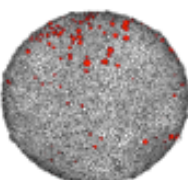

microbiology

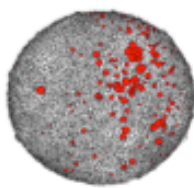

environmental management

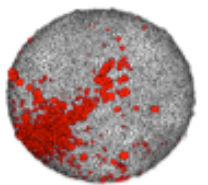

geomorphology

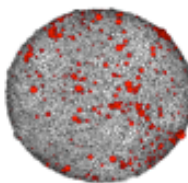

water, science \& technology

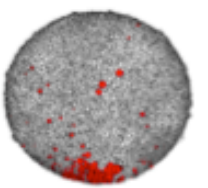

climatology

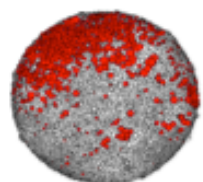

marine \& estuarine

biology

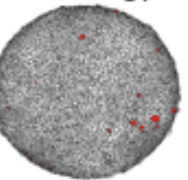

behavioural ecology

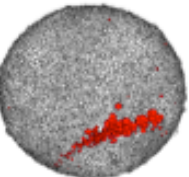

evolutionary ecology

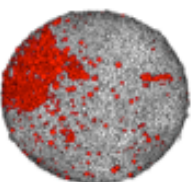

geochemistry

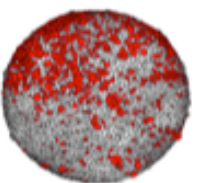

environmental pollution

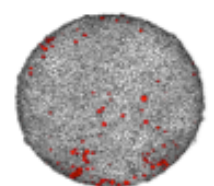

remote sensing

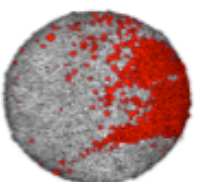

fisheries

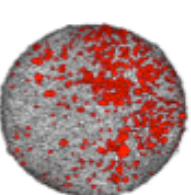

ecology

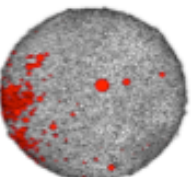

geology

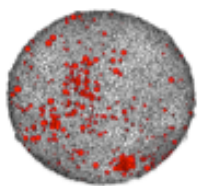

soil science

\& agr water

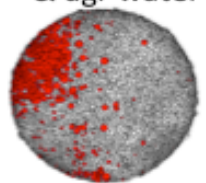

oceanography

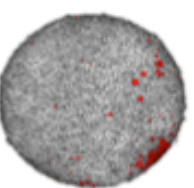

societal issues

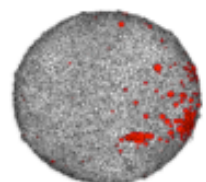

aquaculture

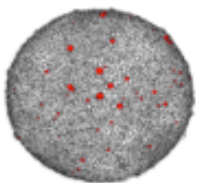

general environm ecology

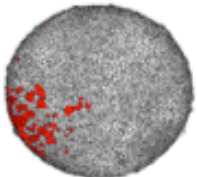

sediment geology

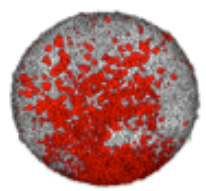

hydrology

\& water resources

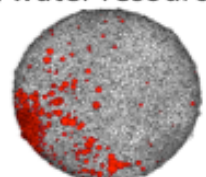

quaternary

science

Fig. 4 Topical scope of all river research fields (including societal issues). ${ }^{11}$

\footnotetext{
${ }^{11}$ Nodes in the figures represent papers whereby the relations between articles are based on similarity in terms of word-reference combinations. The mapping has been partitioned and colored in separate 'layers' according to the research field affiliation of the individual papers.
} 
Overviewing the complete field-configuration of the topics mapping, the previously observed division in meta-fields is recognizable again; the upper half of the mapping presents the ecological sciences with aquatic ecological science positioned at the edge and general ecology lying more to the center. Hydrology \& water resources is concentrated at center-bottom and the geosciences are found at the lower left. Environmental pollution is more spread out across the ecological sciences region. Core fields like limnology and fisheries $\&$ fish research cover a large part of the topics map of river science, along with marine \& estuarine biology. Ecology itself is more heterogeneous and spread out, indicating a wide topical scope. Water science \& technology and soil science are heterogeneous fields as well. Soil science and hydrology \& water resources have shared topics. The link between these fields is also apparent from their mutual citation streams (Fig. 3). The core field hydrology \& water resources field covers a broad topical scope of research issues. Part of this field shows shared topical interest with ecology and environmental management, and with geomorphology. This latter field overlaps with ecology as well. Furthermore, fig. 4 makes clear that the fields of oceanography and geochemistry have considerable topical overlap. This concerns fluxes and loading of organic carbon and nutrients from river basins into oceanic systems as can be derived from the main topics in which both fields are involved (see also Table 4). Finally, the societal topics are presented in a separate visualization and it can be seen that they cluster quite strongly in a specific part of the hydrology \& water research meta-field.

\section{Discussion \& conclusions}

In this study the scholarly output of river research was analyzed using bibliometric techniques with the aim to investigate claims and calls for cross-disciplinary research endeavors (Palmer and Bernhardt 2006; McCulloch 2007). Such a quantitative evaluation of river research seems timely, given the growing body of literature expressing the need for research crossing traditional academic boundaries in support of understanding and managing the socialecological complexity of rivers (Hillman et al. 2008; Vugteveen et al. 2006; Brierley and Fryirs 2008; Surridge and Harris 2007).

The availability of extensive publication databases makes river science amenable to bibliometric indicators, and enables to investigate its dynamics. That leads to a study based only on research output published in peer reviewed scientific journals. Differences exist in publication traditions between scientific disciplines. In the social sciences and humanities, also books provide an important publication format whereas technical fields intensively use conference proceedings. In water related research this is about 25\% (Van den Besselaar and Horlings 2010), which means that journals are the dominant form of communicating research in river science. Therefore, our analysis results in a valid representation of the field. However, including other publication types such as reports may add the applied (transdisciplinary) part of river science in a more detailed way. This we may address in a next study. We will now first discuss the findings about cross-disciplinarity in river science, and then draw conclusions about our approach and method to study cross-disciplinarity.

(i) We started our study mapping river research within the disciplinary landscape and found that river science has not (yet) emerged as an interdisciplinary research field but is performed in four core disciplinary fields: limnology, fisheries \& fish research, hydrology \& water resources, and geomorphology. Overall this structure confirms what other authors identified 
as the main components of a scientific framework for studying the biophysical functioning of rivers, i.e. river ecology, hydrology and fluvial geomorphology (Poole 2002; Dollar et al. 2007; Thoms and Parsons 2002; Mika et al. 2008). As discussed above, cross-disciplinarity is related to the evolution of the disciplinary landscape. Therefore we also made a map of river science in 1998. We factor-analyzed the 1998 journal citation network in a similar way as presented for 2008. We observed growth of the relevant fields in terms of the number of journals, but overall there appear to be no meaningful changes between 1998 and 2008 with respect to the position of river research in the scientific landscape.

Closer examination of disciplinary orientations and cross-disciplinary patterns showed a division of river science in distinct clusters of fields, i.e. meta-fields broadly covering biological and ecological sciences, environmental sciences, the geo- and geochemical sciences and the hydrological sciences (Fig. 1; Table 3). The knowledge flows were shown to be much stronger within than between these meta-fields, although even within the meta-fields, cross-field citations are relatively scarce. This suggests that traditional disciplinary divisions between the biological, environmental and physical dimensions of river system research are still prominent.

Ecology was identified as a primary research field in the river science citation network and is found to be the most cited across all fields (Table 4). This suggests that the field of ecology has become an authoritative knowledge reference underlying river research. This finding fits with an observed shift in river (management) approaches away from an engineering-based to an ecosystem-based water management paradigm (Brierley and Fryirs 2008), and is also supported by the fact that hydraulic engineering did not show up as a separate field in our mapping. Based on a quick scan, the citation environment of hydraulic engineering journals constitutes a network adjacent to what defines river science in this paper.

Despite calls for cross-disciplinary fields such as eco-geomorphology, hydroecology or hydromorphology (Vaughan et al. 2009; Hannah et al. 2004; Thoms and Parsons 2002) the map of river science does not show the arrival of these fields. Nor do we observe a connection with relevant social science research.

These findings are in line with observations by Porter \& Rafols (2009) who examined the degree of interdisciplinarity in mathematics, physics, biology, engineering, medicine and neurosciences. They concluded that science is becoming more interdisciplinary, but in small steps - drawing mainly from direct neighboring fields and only modestly increasing the connections to distant cognitive areas, like social scientific fields in the case of river science.

(ii) In the next step research topics were analyzed in order to provide deeper understanding of the cross-disciplinary nature of river research fronts. This demonstrated that although river science operates in a 'traditional' disciplinary mode as indicated by the field mapping, various research topics represent a combined contribution of disciplinary research, which implies multi-disciplinary research efforts at the operational research level (Tress et al. 2005b). Major topics address the interface of hydrology \& water resources, geomorphology and ecology (Poole 2002; Dollar et al. 2007; Thoms and Parsons 2002) and concern the study of systemic cycles, interactions and dynamics at the interface of these disciplines (see Table 5).

The complex societal context of riverine management issues not only demands understanding from the natural sciences but also from the social sciences including psychology, sociology, geography, political science, economics and policy studies (Vugteveen et al. 2006; Pahl- 
Wostl et al. 2007; Hillman 2009; Lenders and Knippenberg 2005; Brierley and Fryirs 2008; Surridge and Harris 2007). Thorp et al (2007) - in their presentation of the International Society for River Science (ISRS) - mention social science, economics, management and policy as relevant to river science next to hydrology \& water resources, geomorphology, ecology and chemistry. We analyzed whether current multidisciplinary river research includes research beyond natural science. We did find planning and management issues to be part of river science research, evidenced by the presence of an environmental management field, and by several management related research topics mainly within the hydrology \& water resources field (Table 5). The cross-disciplinary orientation of this latter field can be attributed mainly to the water resource journals, which have a broader scope than the hydrology research journals, and which consider water resources in their societal context. However, river research literature does hardly cite social science literature, suggesting that one is reinventing the wheel instead of using what is available. This is in line with Botey et al. (2012), who found that studies related to ecosystem management are dominated by the philosophical, ontological, and epistemological preferences of natural science.

(iii) Our analysis did not confirm that research on river issues in their societal context produces the type of knowledge referred to by Hillman (2009) as phronesis; i.e. contextual and place-dependent knowledge derived from practical experience and values at the local level and applied in a particular socio-political setting. This type of transdisciplinary knowledge is considered necessary to advance river management next to techne or applied "know-how", as in art, craft or technology and episteme or "know-why", scientific knowledge that is universally applicable. Our results thus support Hillman's observation that claims for a paradigm shift based on the full inclusion of the three mentioned knowledge types in river management must be treated with considerable caution (Hillman 2009). Qualitative approaches to the development of river science (Van Hemert 2008; Van Hemert and Van der Meulen 2011), based on interviews and document analysis, often sketch a picture where wishes and aims dominate, and not so much the de facto trends in a research field. The advantage of the quantitative approach in this study is to deliver the latter.

(iv) The local and practical (transdisciplinary) integration of river science in everyday engineering and social interventions may not proceed through paper-based communication of research results, as we noted earlier. Other forms of interaction may be relevant here as well, such as co-researching and collaboration between researchers and river professionals and policy makers. Future research on these collaborative relations may reveal this in more detail.

(v) Finally, we introduced an approach to cross-disciplinarity based on a two level analysis of disciplinary change and research front dynamics. The application of the approach on the river research case suggests its usefulness. At the level of the research front, most topics combine contributions from multiple research fields. This signals emerging multi-disciplinary research activities in river science. By combining this with an analysis of the topological structure of the disciplinary environment of river research, it becomes clear that the multidisciplinary research feeds back into the constituent individual disciplines, without any (early) signs interdisciplinary integration at the field research level. No new clustered research activities outside the boundaries of the established disciplines are visible yet. Actually, despite all the multidisciplinary activities within river research, the 2008 map suggests a firm stability of the disciplinary landscape. For the time being, claims about interdisciplinary river science remain presumptions. 


\section{Acknowledgments}

This study has been partly financed by the Interdepartmental Institute Science \& Society of the Radboud University Nijmegen (grant W\&S 2004-04), and by the Kennis voor Klimaat (Knowledge for Climate) program. Thanks to Mieke van Hemert for providing input when discussing the set up of the project, to André Somers for assistance with the SAINT Toolbox, to Jan Hendriks, Rob Leuven and two anonymous reviewers for providing valuable comments on earlier drafts.

\section{References}

Benda LE, Poff NL, Tague C, Palmer MA, Pizzuto J, Cooper S, Stanley E, Moglen G (2002) How to Avoid Train Wrecks When Using Science in Environmental Problem Solving. Bioscience 52 (12): $1127-1136$

Blondel VD, Guillaume J-L, Lambiotte R, Lefebvre E (2008) Fast unfolding of communities in large networks. Journal of Statistical Mechanics: Theory and Experiment (10): P10008.

Bond B (2003) Hydrology and ecology meet - and the meeting is good. Hydrological Processes 17 (10): 2087-2089.

Bordons, M., Morillo, F., \& Gomez, I. (2004). Analysis of cross-disciplinary research through bibliometric tools. In: H. F. Moed, W. Glänzel, \& U. Schmoch (Eds.), Handbook of quantitative science and technology research. Dordrecht: Kluwer. pp. 437-456

Botey, A. P., Garvin, T., \& Szostak, R. (2012). Ecosystem Management Research: Clarifying the Concept of Interdisciplinary Work. Interdisciplinary Science Reviews 37 (2), 161-178.

Boulton AJ, Piégay H, Sanders MD (2008) Turbulence and Train Wrecks: Using Knowledge Strategies to Enhance the Application of Integrative River Science in Effective River Management. In: Brierley GJ, Fryirs KA (eds) River Futures: An Integrative Scientific Approach to River Repair. Island Press, Washington DC, pp 28-39

Brierley GJ, Fryirs KA (2008) Moves Toward an Era of River Repair. In: Brierley GJ, Fryirs KA (eds) River Futures: An Integrative Scientific Approach to River Repair. Island Press, Washington DC, pp 3-15

Buter, R., Noyons, E., \& Van Raan, A. (2011). Searching for converging research using field to field citations. Scientometrics 86 (2), 325-338.

Cullen P (1990) The turbulent boundary between water science and water management. Freshwater Biology 24 (1): 201-209

Dollar ESJ, James CS, Rogers KH, Thoms MC (2007) A framework for interdisciplinary understanding of rivers as ecosystems. Geomorphology 89 (1-2): 147-162

Fujigaki Y, Quality control and validation boundaries in a triple helix of university-industrygovernment: "Mode 2" and the future of university research. Social Science Information, 39 (4): 635-655.

Gallopin GC, Funtowicz S, O'Connor M, Ravetz J (2001) Science for the Twenty-First Century: From Social Contract to the Scientific Core. International Social Science Journal 53 (168): 219-229 
Goldstone RL, Leydesdorff, L (2006) The import and export of cognitive science. Cognitive Science 30: 983-993.

Hannah DM, Wood PJ, Sadler JP (2004) Ecohydrology and hydroecology: A 'new paradigm'? Hydrological Processes 18 (17): 3439-3445

Hanneman RA, Riddle M (2005) Introduction to social network methods. Online book, accessed $01 / 07 / 2014$

Hillman M (2009) Integrating Knowledge: The Key Challenge for a New Paradigm in River Management. Geography Compass 3 (6): 1988-2010

Hillman M, Brierley GJ, Fryirs KA (2008) Social and Biophysical Connectivity of River Systems. In: Brierley GJ, Fryirs KA (eds) River Futures: An Integrative Scientific Approach to River Repair. Island Press, Washington DC, pp 125-145

Kates RW, Clark WC, Corell R, Hall JM, Jaeger CC, Lowe I, McCarthy JJ, Schellnhuber HJ, Bolin B, Dickson NM, Faucheux S, Gallopin GC, Grubler A, Huntley B, Jager J, Jodha NS, Kasperson RE, Mabogunje A, Matson P, Mooney H, Moore Iii B, O'Riordan T, Svedlin U (2001) Environment and development: Sustainability Science. Science 292 (5517):641-642

Kopcsa A, Schiebel E (1998) Science and technology mapping: A new iteration model for representing multidimensional relationships. Journal of the American Society of Information Science 49 (1): 7-17

Lancichinetti, A., \& Fortunato, S. (2009). Community detection algorithms: A comparative analysis. Physical Review E 80 (5), 056117.

Lenders HJR, Knippenberg L (2005) The temporal and social dimensions of river rehabilitation : towards a multi-dimensional research perspective. Archiv für Hydrobiologie Supplementband Large Rivers 15 (1-4): 119-131

Leydesdorff, L. (2007). "Betweenness Centrality" as an Indicator of the "Interdisciplinarity" of Scientific Journals. Journal of the American Society for Information Science and Technology, 58 (9): 1303-1309.

Liu, Y.X., Rafols, I., \& Rousseau, R. (2012). A framework for knowledge integration and diffusion. Journal of Documentation 68 (1), 31-44.

Klein, J. T. 2004. Prospects for transdisciplinarity. Futures 36: 515-526.

McCulloch CS (2007) Integrating Research for Water Management: Synergy or Dystopia? Water Resources Management 21 (12): 2075-2082

Merkx F, Van den Besselaar P (2008) Positioning indicators for cross-disciplinary challenges: the Dutch coastal defense research case. Research Evaluation 17: 4-16

Mika S, Boulton A, Ryder D, Keating D (2008) Ecological Function in Rivers: Insights from Crossdisciplinary Science. In: Brierley GJ, Fryirs KA (eds) River Futures: An Integrative Scientific Approach to River Repair. Island Press, Washington DC, pp 85-99

Morillo, F., Bordons, M., \& Gómez, I. (2003). Interdisciplinarity in science: A tentative typology of disciplines and research areas. Journal of the American Society for Information Science and Technology 54 (13), 1237-1249.

Naiman RJ (1999) A Perspective on Interdisciplinary Science. Ecosystems 2 (4): 292-295 
Newman M.E.J., Networks, an introduction. Oxford University Press, 2010.

Nowotny, H., Scott, P., \& Gibbons, M. (2003). Introduction: `Mode 2' Revisited: The New Production of Knowledge. Minerva 41 (3) 179-194.

Pahl-Wostl C, Craps M, Dewulf A, Mostert E, Tabara D, Taillieu T (2007) Social learning and water resources management. Ecology \& Society 12 (2):5

Palla, G., Derenyi, I., Farkas, I., \& Vicsek, T. (2005). Uncovering the overlapping community structure of complex networks in nature and society. Nature $\mathbf{4 3 5}$ (7043), 814-818.

Palmer MA, Bernhardt ES (2006) Hydroecology and river restoration: Ripe for research and synthesis. Water Resources Research 42 (3): W03S07

Petts G, Nestler J, Kennedy R (2006) Advancing Science for Water Resources Management. Hydrobiologia $\mathbf{5 6 5}$ (1): 277-288

Poole GC (2002) Fluvial landscape ecology: addressing uniqueness within the river discontinuum. Freshwater Biology 47 (4): 641-660

Porter, A. L., \& Rafols, I. (2009). Is science becoming more interdisciplinary? Measuring and mapping six research fields over time. Scientometrics 81 (3), 719-745.

Porter, A. L., Roessner, J. D., Cohen, A. S., \& Perreault, M. (2006). Interdiscipinary research: Meaning, metrics and nurture. Research Evaluation 15 187-196.

Rafols, I., Leydesdorff, L., O’Hare, A., Nightingale, P., \& Stirling, A. (2012). How journal rankings can suppress interdisciplinary research: A comparison between innovation studies and business \& management. Research Policy 41 (7), 1262-1282.

Rafols, I., \& Meyer, M. (2010). Diversity and Network Coherence as Indicators of Interdisciplinarity: Case studies in bionanoscience. Scientometrics 82 (2), 263-287.

Rinia, E.J., Van Leeuwen, T.N., Bruins, E.P.W., Van Buren, H.G., \& Van Raan, A.F.J. (2002). Measuring knowledge transfer between fields of science. Scientometrics 54 (3), 347-362.

Somers A, Gurney T, Horlings E, Van den Besselaar P (2009) Science assessment integrated network toolkit (SAINT): a scientometric toolbox for analyzing knowledge dynamics. Rathenau Institute, The Hague

Surridge B, Harris B (2007) Science-driven integrated river basin management: a mirage? Interdisciplinary Science Reviews 32 (3): 298-312

Thoms MC, Parsons M (2002) Eco-geomorphology: an interdisciplinary approach to river science. International Association of Hydrological Science \& Culture 276: 113-120

Thorp JH, Stanford JA, Thoms MC, Petts GE (2007) Global partnerships and the new international society for river science (ISRS). River Research and Applications 23 (1): 1-5

Tress B, Tress G, Fry G (2005a) Integrative studies on rural landscapes: policy expectations and research practice. Landscape Urban Planning 70 (1-2): 177-191

Tress G, Tress B, Fry G (2005b) Clarifying Integrative Research Concepts in Landscape Ecology. Landscape Ecology 20 (4): 479-493

Van den Besselaar P, (forthcoming) Interdisciplinarity as disciplinary change. 
Van den Besselaar P, Heimeriks G (2001) Disciplinary, Multidisciplinary, Interdisciplinary - Concepts and Indicators In: Proceedings ISSI Conference on Scientometrics and Informetrics. Sydney, Australia

Van den Besselaar P, Heimeriks P (2006) Mapping research topics using word-reference cooccurrences: A method and an exploratory case study. Scientometrics 68 (3): 377-393

Van den Besselaar P, Horlings E (2010) Focus en massa in het wetenschappelijk onderzoek?: de Nederlandse onderzoeksportfolio in internationaal perspectief. Rathenau Institute, The Hague

Van den Besselaar P, Leydesdorff L (1996) Mapping change in scientific specialties: A scientometric reconstruction of the development of artificial intelligence. Journal of the American Society for Information Science and Technology 47 (6): 415-436

Van Hemert AJ (2008) Making rivers modular. Emerging river science 1980-2005. PhD thesis, Twente University, Enschede

Van Hemert M, Van der Meulen B (2011) Kennis bundelen in onderzoeksprogramma's. Rivier- en kustonderzoek in Nederland. Rathenau Instituut, Den Haag

Van Kerkhoff L (2005) Integrated research: concepts of connection in environmental science and policy. Environmental Science \& Policy 8 (5): 452-463

Van Raan, A.F.J., \& van Leeuwen, T.N. (2002). Assessment of the scientific basis of interdisciplinary, applied research. Application of bibliometric methods in nutrition and food research. Research Policy 31 (4), 611-632.

Vaughan IP, Diamond M, Gurnell AM, Hall KA, Jenkins A, Milner NJ, Naylor LA, Sear DA, Woodward G, Ormerod SJ (2009) Integrating ecology with hydromorphology: a priority for river science and management. Marine Freshwater Ecosystems 19 (1): 113-125

Vugteveen P, Leuven RSEW, Huijbregts MAJ, Lenders HJR (2006) Redefinition and Elaboration of River Ecosystem Health: Perspective for River Management. Hydrobiologia 565 (1): 289-308

Wagner, C. S., Roessner, J. D., Bobb, K., Klein, J. T., Boyack, K. W., Keyton, J., Rafols, I., \& Börner, K. (2011). Approaches to Understanding and Measuring Interdisciplinary Scientific Research (IDR): A Review of the Literature. Journal of Informetrics 5 (1) 14-26.

Wear DN (1999) Challenges to Interdisciplinary Discourse. Ecosystems 2 (4): 299-301

Zitt, M. (2005). Facing diversity of science: A challenge for bibliometric indicators. Measurement 3 (1) $38-49$. 